\title{
AS NOÇÕES DE "MODERNO" NA FOTOGRAFIA DO FOTO-CINE CLUBE BANDEIRANTE
}

Vanessa Sobrino Lenzini

A produção coletiva do Foto-Cine Clube Bandeirante (FCCB) ganhou destaque em meio à formação de uma história da fotografia no Brasil, durante a década de 1950, em paralelo à construção da noção de 'moderno' na fotografia. Na recente historiografia que busca pensar a produção fotográfica nacional, a experiência do FCCB atestaria a fase moderna, embora distante do que se consolidou como marco do modernismo artístico - a Semana de Arte Moderna de 1922.

Pensar os sentidos que se apresentam como 'moderno' na fotografia do FCCB, entretanto, pressupõe voltar-se à documentação deste Clube e observar de que forma os protagonistas desta história se auto-definiam como tal, e do mesmo modo, não prescinde mapear o contexto que o Clube o os fotógrafos estavam inseridos na rede de suas sociabilidades. Para a análise desse conceito na fotografia busca-se distanciamento que possibilite diferenciar o 'moderno' divulgado pela documentação e o que se definiu pela historiografia.

A documentação para esta analise contempla os artigos publicados no FCCB-Boletim ${ }^{1}$, principalmente durante 1948-1951. A partir de 1948, nota-se uma mudança na publicação, pela introdução de artigos traduzidos e adaptados de livros e revistas estrangeira, que discutem a cerca de uma nova prática fotográfica. No âmbito imagético, vê-se uma correspondência de mudança de perspectiva neste ano, pela publicação das fotografias participantes dos Salões Internacionais de Arte Fotográfica ${ }^{2}$, nos catálogos de tais salões.

De imediato, pode-se perceber a carga simbólica do nome escolhido para o Clube: Bandeirante. Referência a uma tradição paulista, de forte caráter identitário, alude aos ideais de progresso do contexto de vertiginoso crescimento populacional e de urbanização na cidade de São Paulo, durante as décadas de 1940 e 1950. ${ }^{3}$ Remetendo a um passado heróico dos bandeirantes 'desbravadores de terras', o nome oferece uma idéia do que o FCCB buscava representar na fotografia realizada no Brasil. No primeiro artigo sobre a história do clube, publicado no FCCB-Boletim descreve o momento anterior ao Clube como um ambiente hostil á fotografia, enaltecendo a função do FCCB:

Não era possível permitir que a arte fotográfica, como tal cultivada nos mais longínquos recantos do mundo, continuasse entre nós ignorada, relegada ao mais completo esquecimento, entre nós que nos orgulhavamos de ser a capital artística do Brasil.. ${ }^{4}$.

\footnotetext{
1 A primeira publicação do Foto-Cine Clube Bandeirante-Boletim foi em 1946, e tinha periodicidade mensal. Circulava pelo fotoclubes do interior do estado, e de outras capitais. A partir de 1948, apresenta um preço para ser vendido no exterior. Em suas páginas eram publicados informes sobre as atividades do Clube, - como as excursões, os concursos, os Salões -, assim como artigos que discutiam sobre a natureza da fotografia e atividades fotográficas.

${ }^{2}$ Realizados na Galeria Prestes Maia, no centro de São Paulo, pelo Foto-Cine Clube Bandeirante.

3 Ao analisar os festejos do IV Centenário da Cidade de São Paulo em 1954, Arruda diz que "o evento exprimia, na verdade, o desejo de projetar uma imagem da São Paulo progressista e moderna, o que tornou o projeto comemorativo um ritual de celebração do poder dos paulistas”. ARRUDA, Maria Arminda do Nacimento. Metrópole e Cultura: São Paulo no meio do século XX Bauru, SP: EDUSC, 2001. p. 72

4 "Um pouco de história" in FCCB-Boletim, Ano I, n¹, p.3.
} 
Nota-se a defesa de um pioneirismo paulista na divulgação da fotografia como manifestação artística, seguindo um movimento internacional, que se colocava contra a massificação do processo fotográfico e as concepções correntes da fotografia como cópia da realidade.

Essa defesa da fotografia como arte, que se acha divulgado na documentação do momento fundador do FCCB, converge com os ideais do pictorialismo na fotografia, inicialmente recorrente no Photo Club Brasileiro, fundado em 1923, no Rio de Janeiro. Maria Teresa de Mello, que trabalhou a história deste Clube aborda que: "a concepção artística da fotografia só ganha expressividade no Brasil com o surgimento do fotoclubismo, que toma como diretriz estética o movimento pictorialista internacional'. ${ }^{5}$ Mello levanta duas ressalvas na especificidade da fotografia pictorialista no Brasil. Considera a tradição figurativa da pintura produzida pela Escola Nacional de Belas Artes e a produção das revistas ilustradas, cujo traço forte da caricatura forneceu uma conotação mais social às imagens fotográficas.

No texto da capa do primeiro número do Boletim, com a preocupação em defender o aspecto artístico da fotografia, já se delineava um debate que se repetiria ao longo das publicações do Boletim - principalmente durante o período de 1948-1953-, que se pauta no conflito entre uma fotografia moderna e uma fotografia pictorialista ou acadêmica:

Poder-se-á estar ou não de acôrdo com alguns dos conceitos que, refletindo as tendências da época (impressionismo, abstracionismo, e outros tantos 'ismos' que estão invadindo tudo, procurando 'governar' inclusive as artes) apenas julgam bom o que é 'moderno' quando não extravagante, enquanto muita cousa ótima é taxada de 'acadêmica' ou 'passadista'.

Interessante notar que este texto foi escrito pelo sócio-fundador Eduardo Salvatore, que em 1951 defenderia e produziria uma obra fotográfica crítica ao pictorialismo, dentro do postulado que definia uma fotografia 'moderna'.

Em História da Fotografia Moderna no Brasil, Helouise Costa e Renato Rodrigues ${ }^{8}$ analisam a fotografia moderna a partir das inovações formais e técnicas da produção fotográfica do FCCB, em contraposição à tradição de uma fotografia pictorialista. Ao privilegiar a produção de alguns fotógrafos do FCCB, relevantes para essa nova abordagem na fotografia, Costa \& Rodrigues dividem em três fases essa formação moderna: os pioneiros ${ }^{9}$, a Escola Paulista ${ }^{10}$, e a

${ }_{5}^{5}$ MELLO, Maria Teresa Bandeira de. Arte e Fotografia: o movimento pictorialista no Brasil Rio de Janeiro: FUNARTE, 1998. p. 65

"SALVATORE, Eduardo. "A margem do nosso IV Salão” in FCCB-Boletim, Ano I, n¹, maio de 1946.

${ }^{7}$ No artigo intitulado "Considerações sobre o momento fotográfico", no FCCB-Boletim, Ano VI, no67, nov.1951, Salvatore discute sobre os fotógrafos que produzem suas fotografias de orientação pictorialista, somente com o intuito de acompanharem as tendências dos salões. Ele escreve que: "Muitos outros, entretanto - e entre estes estão os 'bandeirantes' - não temem sair dos postulados acadêmicos, procurando novos modos de expressão, sobrepondo á mera representação o espirito, o conteúdo, os valores humanos, através de uma interpretação própria, embora isso lhes possa acarretar maior soma de trabalhos recusados nos salões ainda apegados ao "pictorialismo". Em comparação com o texto que abre a publicação dos boletins, em 1946, nota-se uma inversão das tendências fotográficas defendidas.

8 COSTA, Heloise \& RODRIGUES, Renato. A Fotografia Moderna no Brasil Rio de Janeiro:Editora da UFRJ: IPHAN: FUNARTE, 1995.

${ }_{9}$ Thomaz Farkas, Geraldo de Barros, José Yalenti e German Lorca.

10 Aponta como principais os fotógrafos Eduardo Salvatore, Marcel Giró, Roberto Yoshida, Gertrudes Altschul, Ademar Manarini, Gaspar Gasparian, Ivo Ferreira Da Silva e João Bizarro Nave Filho 
diluição da experiência moderna ${ }^{11}$. Os autores atribuem o surgimento e o desenvolvimento de uma fotografia 'moderna' e 'brasileira' ao somatório das pesquisas individuais dos fotógrafos do FCCB.

Já Rubens Fernandes Junior, em Labirinto e Identidades, constrói um panorama da produção fotográfica brasileira entre 1946-1998, enfatizando a experiência moderna restrita apenas à produção de dois fotógrafos, Geraldo de Barros e José Oiticica Filho. Entretanto, o autor discute a respeito da concepção de Costa \& Silva, em que a fotografia moderna estaria vinculada à experiência do FCCB:

ainda que buscassem a ruptura como forma de trabalho, trazendo o espírito da modernidade para a fotografia brasileira, foram Geraldo de Barros (1923-98), em São Paulo, e mais tarde José Oiticica Filho (1906-64), no Rio de Janeiro, que explicitaram uma concepção mais arrojada do fazer fotográfico, incluindo um profundo questionamento dos limites da própria concepção da fotografia. Essas iniciativas foram responsáveis pela verdadeira experiência moderna da fotografia brasileira ${ }^{12}$.

Em uma perspectiva mais ampla, Annateresa Fabris analisa os discursos da modernidade e sobre a modernidade, e afirma que só podem ser compreendidos como:

partes essenciais de um conjunto de construções teóricas produzidas em tempos e em espaços historicamente determinados, sem qualquer possibilidade de aspirar a durações e validades indeterminadas ${ }^{13}$.

$\mathrm{Na}$ resenha da obra de Costa \& Rodrigues, Fabris questiona a ausência do pictorialismo dentro dessa 'modernidade' na fotografia brasileira. Para Fabris, o pictorialismo foi moderno em sua época pois problematizou a natureza mecânica da fotografia e conferiulhe estatuto artístico, com a prática de intervenções na cópia fotográfica e pela busca de modelos na pintura clássica. Neste sentido, esse questionamento pode ser pensado também sobre a idéia de Rubens Fernandes Junior que vagamente distinguiu um "espírito de modernidade" na fotografia, de uma noção de "experiência moderna". Se a definição de "fotografia moderna", para Fernandes Junior, caracteriza-se pelo "questionamento dos limites da própria concepção da fotografia", o pictorialismo deveria estar inserido neste debate, por indagar sobre a natureza mecânica do meio fotográfico, na senda de Fabris.

O debate em torno de uma definição do "moderno", constante na historiografia sobre a fotografia e presente nos artigos do FCCB-Boletim, mostra-se polissêmico. Em comum apresentam o "moderno" como ruptura que porta o novo, contraponto de uma tradição. O termo "moderno" na fotografia não possuiu uma definição unívoca, esteve em constante disputa. Seu uso e sua repercussão, muitas vezes, implicaram em diferenciações, afirmações e contestações de uma cultura frente à outra.

No caso da fotografia do FCCB, o 'moderno' foi divulgado no Boletim em contraposição ao pictorialismo. Entretanto, numa análise mais atenta das idéias defendidas nos artigos, percebe-se que muito do que se discutia como 'moderno' no FCCB, freqüentou um

\footnotetext{
${ }^{11}$ Estariam inseridos fotógrafos como Eduardo Ayrosa, José Martins Dias, Claudio Pugliese, José Mauro Pontes, Emil Issa, Cláudio Pugliese, José Martins Dias e Nélson Peterline.

12 JUNIOR, Rubens Fernandes. Labirinto e Identidades: panorama da fotografia no Brasil (1946-1998). São Paulo: São Paulo: Cosac \& Naify, 2003.

${ }^{13}$ FABRIS, Annateresa. "Modernidade e Vanguarda: o caso brasileiro" in FABRIS, Annateresa. (org.) Modernismo e Modernidade no Brasil. São Paulo: Mercado de Letras, 1994.
} 
debate que era interno ao pictorialismo, inclusive no Foto Club Brasileiro. Como exemplo, a intervenção manual era muito discutida, de modo geral, por esses artigos publicados no FCCBBoletim que eram críticas diretas ao pictorialismo, pois alegavam que essa técnica negava as peculiaridades do meio fotográfico, recorrendo à pintura. Mello apresenta que no Photo Club Brasileiro:

a questão central sobre a qual surgem as discordâncias mais fortes é a de saber se a intervenção do fotógrafo sobre a prova deve ser manual - à maneira do pintor - ou realizada com recursos exclusivamente fotográficos. ${ }^{14}$.

Neste sentido, pensar em continuidades, ao invés de rupturas, talvez contribua na análise de uma proposta "moderna" que intencionava negar um passado recente e, ao mesmo tempo compartilhava propostas comuns.

Em certa abordagem sobre o 'moderno', David Harvey privilegia tais continuidades. Para ele, os artistas modernos "gastavam muito mais energias lutando entre si e com as suas tradições para vender seus produtos do que o faziam engajando-se na ação política real." ${ }^{15} \mathrm{O}$ posicionamento do artista frente a uma cultura urbana, tornou-se para Harvey chave central para entender as continuidades históricas negadas pelo modernismo. Assim afirmou:

Como Baudelaire logo percebeu, se o fluxo e a mudança, a efemeridade e a fragmentação formavam a base material da vida moderna, então a definição de uma estética modernista dependia de maneira crucial do posicionamento do artista diante desses processos ${ }^{16}$.

Esta perspectiva põe em discussão trabalhos que abordam o artista como ponto único, isolado de qualquer contexto e redes de sociabilidade que compartilha. Como por exemplo, o trabalho de Rubens Fernandes Junior, que atribui a dois fotógrafos e suas obras uma ruptura na concepção fotográfica, isolados de suas experiências artísticas e fotográficas. Com este recorte, o autor não pondera os conflitos e debates existentes no interior do Clube e a posição de cada fotógrafo no coletivo. De certa forma, as relações entre os fotógrafos ou entre outras pessoas ligadas ao ambiente artístico da época podem ter contribuído com a constituição da noção do 'moderno' na fotografia.

A imagem do artista como ícone tornou-se recorrente na crítica de arte. Dos fotógrafos do FCCB, Geraldo de Barros foi o que mais teve sua imagem afastada da experiência do Clube. Em seus catálogos de exposições fotográficas não existe qualquer menção ao passado fotoclubístico. ${ }^{17}$ No entanto, em 1953, Geraldo de Barros conseguiu junto com Ademar Manarini uma sala especial para a exposição de fotografias do FCCB na II Bienal Internacional de São Paulo. Neste evento a produção do Clube ganhou reconhecimento internacional e

\footnotetext{
${ }^{14}$ Mello. Op. Cit. p.69

${ }^{15}$ HARVEY, David. "Modernidade e Modernismo" in A Condição Pós-Moderna: pesquisa sobre as origens da Mudança Cultural Edições Loyola:São Paulo, 1993. p. 35.

16 Op. Cit. p.28 e 29.

17 BARROS, Geraldo de. Fotoformas São Paulo: Raízes, 1994; Geraldo de Barros, Fotógrafo, MIS _SP; Fotoformas Munique/ Londres/ Nova York: Prestel, 1999; Geraldo de Barros, Fotoformas, Museum Ludwig, Köln (26/08/1999), Sesc Pompéia, São Paulo (3.11 a 3.12.1999) e Musée de L’Elysée, Lausane (jul. a set. 2000); Precursor Rio de Janeiro: Centro Cultural Banco do Brasil, 1996; Jogos de Dados Campinas: UNICAMP. Exposição realizada em homenagem a Ademar Manarini 1920-1989, (MACC, 29.08.1989/ MAM-SP, 02/03.1990).
} 
comentários de personalidades importantes do meio artístico e moderno da época como Walter Gropius, Henri Moore e Max Bill. ${ }^{18}$

Com a atividade de alguns fotógrafos do FCCB junto aos museus de arte de São Paulo, seja em exposições ${ }^{19}$ ou em prestação de serviços ${ }^{20}$, o Clube ganha o olhar de críticos que era voltado apenas para a cena das consideradas grandes artes, como o de Pietro Maria Bardi, Mário Pedrosa e Sérgio Milliet. ${ }^{21}$ Neste caso, o valor do artístico e do 'moderno' agrega-se ao espaço museológico, pois as obras expostas e incorporadas aos acervos portam esses valores, conquistando prestígio artístico e comercial. Essa aceitação reforça-se no costume tradicional de conferir existência e autenticidade à obra de arte, pelo reconhecimento dos museus. Conforme a idéia de Walter Benjamin, "mesmo na reprodução mais perfeita, um elemento está ausente: 0 aqui e agora da obra de arte, sua existência única, no lugar que ela se encontra. É nessa existência única, e somente nela, que se desdobra a história da obra", ${ }^{22}$ e o museu torna-se local privilegiado em que essa arte se agrega ao seu valor de unicidade. No Brasil, Mário Pedrosa, que foi protagonista desse debate do 'moderno' no ambiente artístico, afirmava que:

somente à frente de um museu de arte, dita moderna, é que melhor se pode compreender a natureza intrínseca dessa mesma arte, e, de outro lado, o papel que cabe o museu na avaliação dela ${ }^{23}$.

Neste contexto de musealização das artes, nota-se que concomitante a integração do FCCB a uma cultura urbana e cosmopolita, cria-se redes de sociabilidade que perpassam diversos setores artísticos e intelectuais coevos. Estão presentes nas homenagens fotográficas de Geraldo de Barros², de 1949 á 1951; na produção fotográfica de Thomaz Farkas documentando a construção de Brasília; German Lorca que realizou diversas fotos a partir da construção do parque do Ibirapuera e, Eduardo Salvatore buscando a abstração nos móbiles de Alexander Calder, em exposição no MASP, em 1948. Mesmo na fotografia Colméia, de José Yalenti, composta por formas geométricas do prédio considerado pioneiro da arquitetura

${ }^{18}$ Não foi encontrada até o momento outra referência à respeito da fotografia nas primeiras Bienais de Arte em São Paulo, exceto os comentários feito pelo FCCB-Boletim, anotados por Geraldo de Barros: BARROS, Geraldo de. "A Sala de Fotografia" in F.C.C.B. Boletim Ano VIII, no 87. 1954.

${ }^{19}$ Geraldo de Barros, em 1950, no Masp; Thomaz Farkas, em 1949, no MAM-SP; e German Lorca, no MASP, em 1952.

${ }^{20}$ Geraldo de Barros e Thomaz Farkas montaram o laboratório fotográfico no Masp, para o Instituto de Arte Contemporânea, coordenado por Lina Bo Bardi.

${ }^{21}$ HERKENHOFF, Paulo "Fotografia: o automático e o longo processo de modernidade" in TOLIPAN, Sérigo et alii. Sete ensaios sobre o Modernismo Rio de janeiro: Funarte, 1983. p. $44 \mathrm{Na}$ nota 46, ele localiza "O ano de 1957", por Mário Pedrosa, Jornal do Brasil, 1 fev. 1958; "Fotografia, Arte?” por Walter Zanini, FCCB-Boletim, Ano VII, n92, 1954; "Fotoformas", por P.M. Bardi, Catálogo da exposição, MASP, 1950, transcrito por Aracy Amaral, in Projeto construtivo brasileiro na arte, nota 10; "Suplemento Dominical", Jornal do Brasil, por Ferreira Gullar; FCCBBoletim, por Frederico Morais, Ano 9, n 106, fev. 1959; e idem, por Geraldo Ferraz, Ano 13, no 148, 1965.

22 BENJAMIN, Walter. "A obra de arte na era da reprodutibilidade técnica" in Magia e técnica, arte e politica: ensaios sobre literatura e história da cultura. (trad. Sérgio Paulo Rouanet) São Paulo, SP: Editora Brasiliense, 1987. p.167

23 PEDROSA, Mário. "Arte experimental e museu”, Jornal do Brasil, 16.12.60 in Modernidade Cá e Lá : textos escolbidos IV. (org. Otilia Arantes) São Paulo, SP: EDUSP, 2000.

${ }^{24}$ Homenagem a Picasso, São Paulo, 1949; Homenagem a Paul Klee, São Paulo, 1949; Homenagem a Stravinsky, São Paulo, 1949; Homenagem a Cartier-Bresson, Orléans, Fr, 1951; Retrato de Cláudio Abramo, Veneza, 1951; Máquina de escrever (Homenagem a Homero Silva), São Paulo, 1949; Thalassa...Thalassa (Homenagem a E. Pound), 1949; Ateliê de Vieira da Silva, Paris, Fr, 1951; Homenagem a Simeão Leal, Rio de janeiro, 1950. 
moderna - o edifício do Ministério da Educação, construído a partir do trabalho de Oscar Niemeyer, Lucio Costa e Le Corbusier. Nota-se, no entanto, que a constituição de uma arquitetura urbana estava em comunhão com a formação da "nova" fotografia. Aproxima-se assim à definição de Harvey sobre o moderno:

um fenômeno urbano, ligado ao crescimento urbano, ligado à forte migração para os centros urbanos, com a industrialização e a mecanização, além da reorganização maciça dos ambientes construídos ${ }^{25}$.

Não somente pela relação da chamada fotografia 'moderna' com os museus, e sua integração com outras artes, mas, inclusive, o diálogo com o movimento internacional na fotografia é que se impulsionaram pesquisas no tratamento de novas perspectivas e angulações, privilegiando uma geometrização que buscasse a abstração. $\mathrm{Na}$ acelerada urbanização brasileira dos anos 1940, - com construções civis abundantes e concentração da população em centros urbanos -, a reformulação do espaço ganhou destaque no planejamento das cidades. Em paralelo, os fotógrafos encontraram na construção formal da imagem um campo de pesquisas e vínculo artístico. Este pode ser visto como outro aspecto constituinte da noção de 'moderno' na fotografia.

Os recursos formais utilizados na prática fotográfica eram divulgados nos boletins do FCCB, que a partir de 1948, com a publicação de uma série de artigos traduzidos e adaptados definiam um modelo de fotografia 'moderna'. Nesses artigos destaca-se uma fotografia formada por poucos elementos, suprimida de ornamentos, para que fosse direta ao olhar do observador, e transmitisse uma mensagem ${ }^{26}$. Idéias da vanguarda fotográfica internacional chega à produção do FCCB por meio da repercussão teórica desses artigos publicados no FCCB-Boletim e, em outro flanco, pelo contacto da produção fotográfica nos Salões Internacionais de São Paulo, realizados pelo próprio Clube.

Nesses artigos era constante a idéia de que o fotógrafo deveria valorizar sua expressão individual, buscar novas pesquisas em técnicas que poderiam constituir uma nova estética, e na exploração da fotografia dentro do aparato expressivo que o processo fotográfico dispunha. No aspecto formal, esses fotógrafos sugerem altos contrastes, sombras imensas e temas que circundam o cotidiano urbano. Neste sentido, criticam o excesso de detalhes no recorte fotográfico, as tonalidades suaves e a escolha de temas românticos, literários, de paisagens e de retratos clássicos, para criar distanciamento ao pictorialismo.

Tomado como gesto, publicar fotografias de salões internacionais e artigos estrangeiros pode representar a busca do ideal modernizador, pela qual o FCCB se mobilizava. Da mesma maneira, a idéia de vivenciar um cosmopolitismo se moldava no internacionalismo presente nos Salões, em meio às representações nacionais. No mesmo ano 1948, o da inserção desses artigos no Boletim, os Salões Internacionais de Arte Fotográfica, realizados pelo FCCB na Galeria Prestes Maia no centro de São Paulo também sofreriam modificações. Pela análise da publicação de algumas fotografias escolhidas para os catálogos dos Salões Internacionais de Arte Fotográfica de São Paulo, nota-se uma mudança no que se refere à predominância de tendências fotográficas. Por exemplo, os fotógrafos que ficaram conhecidos como percussores

${ }^{25}$ HARVEY, D. Op. Cit. p. 31

26 "A Missão e o Campo de Ação da Fotografia Moderna" Tibor de Csorgeo in FCCB-Boletim, Ano III, n³1, 1948. 
da fotografia "moderna" no Brasil, Farkas, Albuquerque, Gaspariam e Salvatore, ${ }^{27}$ no VI Salão Internacional de São Paulo, em 1947, estavam voltados a uma fotografia pictorialista, segundo as próprias tendências no interior do Clube.

No catálogo do VII Salão Internacional de São Paulo, nota-se nitidamente a mudança a partir das fotografias publicadas. Salvatore utilizou-se do jogo de luz e sombra, em alto contraste, assim como prescreviam os artigos estrangeiros publicados no Boletim. José Yalenti participou com Evanescentes, que ficaria conhecida pela exploração da perspectiva de um homem sentado a uma escada, que com o abuso de contraste passava a sensação da escada estar sem apoio. Finalmente Farkas, que no VI Salão participava com uma fotografia de paisagem Dois Irmãos, neste buscava se expressar com Reflexos na Praia na vertente "moderna" com um recorte aproximado a uma composição de pedras e reflexos na água.

Confrontando o aspecto teórico com o imagético, divulgado pelos artigos e pelas fotografias de salões e de concursos, nota-se sua correspondência na mudança de tendência plástica praticada, e na alteração de discurso a favor de uma fotografia direta e subjetiva.

As idéias de uma subjetividade adentrando o fotográfico, como uma nova modalidade que conferia o aspecto artístico à fotografia, apareciam por meio de uma subjetividade expressada pelo processo estritamente fotográfico, e não necessariamente na aproximação á pintura com as intervenções pictoriais. Assim como se expressou Jacob Polacow, sóciofundador que teve uma significativa participação na definição de uma proposta teórica moderna para a fotografia produzida pelo Clube:

Como a Arte não tem fronteiras, nada justificaria a jactância de que os brasileiros se fizeram artistas-fotógrafos a sua própria custa, isentos da influência do exterior. Pelo contrário. O que nos tem sido proporcionado pelos Salões Internacionais promovidos anualmente pelo Foto-Cine Clube Bandeirante, nesta capital, constitui-se de uma valia inestimável para a formação de nossa mentalidade artístico-fotográfica ${ }^{28}$.

Para Polacow, após 1948 já não existiam mais diferenças entre a produção nacional, definida pela produção do FCCB, e a produção estrangeira. No entanto, para ele, o novo caráter do FCCB deveu-se a uma ligação direta com as influências da produção fotográfica estrangeiras, que se tornaram preponderantes nos Salões Internacionais do FCCB. Já Salvatore distancia-se da posição de Polacow ao discutir sobre as fotografias dos Salões Internacionais, ele referia-se ao modelo dessas fotografias estarem relacionadas com as tendências fotográficas dos júris dos salões e não, como postulava Polacow, pelas tendências de vanguarda.

Para os fotógrafos, considerados artistas, a cidade tornou-se o local de experiência e vivência da modernidade, assim como sua razão de serem considerados como tais. Tanto que nas fotografias do FCCB, entre 1948-1950, o referente era construído com ênfase no cotidiano e na vida urbana, além das sociabilidades vividas nela. $O$ moderno se constituía a partir do progresso que a cidade poderia oferecer, por meio de um ideal de arquitetura, de urbanização, de industrialização e de internacionalização. Maria Cecília França Lourenço conclui:

O país atravessa período incomum em que as distintas culturas são prestigiadas, seja a esportiva, a artística, e a radiofônica, seja a cultura de massa. O Moderno, que fora modernista nos anos 20, uma causa entre 30 e 50, agora direciona-se para as instituições, acreditando poder funcionar como êmulo para uma sociedade mais justa,

27 Ver em Costa \& Rodrigues, Op. Cit. 1997. p. 46 a 59.

${ }^{28}$ POLACOW, Jacob "Arte Fotográfica em seus aspectos locais" in FCCB- Boletim, Ano IV, nº43,1949. 


\begin{abstract}
fraterna, universal e com menos preconceitos - daí sua grandeza e interesse. Julga-se que a arte detem um poder irrestrito, podendo até interferir no cotidiano, liberar sonhos, utopias e desafios, numa verdadeira reconciliação com a juventude, antes colocada sob suspeição ${ }^{29}$.
\end{abstract}

A experiência do Foto-Cine Clube Bandeirante participou, com a exploração do suporte fotográfico, do projeto político cultural que se afirmava nos anos 50 do século XX. O intercâmbio de idéias, tendências e vanguardas com o diálogo internacional, ocorreram para que a fotografia alcançasse o campo das artes plásticas, não mais como uma imitação da pintura, mas na pesquisa de suas peculiaridades, seus limites e inovações. A representação do referente aproximou a obra do olhar do espectador, seja literalmente, no zoom e na valorização de um recorte com poucos detalhes, ou no direcionamento do "olhar pensativo", isto é, da imagem que necessita que se percorra por toda construção fotográfica para que se entenda o que ela está propondo.

Nesta direção, com a criação do MASP e MAM-SP ocorreu uma transformação no meio institucional. Houve uma consolidação da arte abstrata. Nos moldes de um status artístico conferido antes somente às "grandes artes" visuais, como a pintura e a escultura, por uma brecha se estendeu também à fotografia. O impacto das Bienais de São Paulo acrescentou neste contexto de efetiva participação do grande público, o reconhecimento da crítica sobre as representações artísticas possíveis no suporte fotográfico, o que contribuiu para o contacto da arte com o social, ampliando a esfera de reconhecimento e sociabilização.

\title{
Bibliografia
}

ARRUDA, Maria Arminda do Nacimento. Metrópole e Cultura: São Paulo no meio do século XX Bauru, SP: EDUSC, 2001.

LOURENÇO, Maria Cecília França. Museus Acolhem Moderno. São Paulo, SP: Editora da Universidade de São Paulo, 1999.

CALBET, Javier e CASTELO, Luis. Historia de la Fotografia. Madrid: Acento Editorial. 2002.

HARVEY, David. "Modernidade e Modernismo" in A Condição Pós-Moderna: pesquisa sobre as origens da Mudança Cultural Edições Loyola:São Paulo, 1993.

BENJAMIN, Walter. "A obra de arte na era da reprodutibilidade técnica" in Magia e técnica, arte e política: ensaios sobre literatura e história da cultura. (trad. Sérgio Paulo Rouanet) São Paulo, SP: Editora Brasiliense, 1987. p.167

PEDROSA, Mário. “Arte experimental e museu”, Jornal do Brasil, 16.12.60 in Modernidade Cá e Lá: textos escolhidos IV. (org. Otilia Arantes) São Paulo, SP: $\quad$ EDUSP, 2000

HERKENHOFF, Paulo "Fotografia: o automático e o longo processo de modernidade" in TOLIPAN, Sérigo et alii. Sete ensaios sobre o Modernismo Rio de janeiro: Funarte, 1983.

\footnotetext{
${ }^{29}$ LOURENÇO, Maria Cecília França. Museus Acolhem Moderno. São Paulo, SP: Editora da Universidade de São Paulo, 1999. P. 22
} 
FABRIS, Annateresa. "Modernidade e Vanguarda: o caso brasileiro" in FABRIS, Annateresa. (org.) Modernismo e Modernidade no Brasil. São Paulo: Mercado de Letras, 1994.

JUNIOR, Rubens Fernandes. Labirinto e Identidades: panorama da fotografia no Brasil (19461998). São Paulo: São Paulo: Cosac \& Naify, 2003.

MELLO, Maria Teresa Bandeira de. Arte e Fotografia: o movimento pictorialista no Brasil Rio de Janeiro: FUNARTE, 1998. 